Volume 9, No.1.3, 2020

International Journal of Advanced Trends in Computer Science and Engineering

Available Online at http://www.warse.org/IJATCSE/static/pdf/file/ijatcse0991.32020.pdf

https://doi.org/10.30534/ijatcse/2020/0991.32020

\title{
Design to Encourage Reframing and Transformations through Digital Story telling and Analogical Thinking
}

\author{
Chien-Sing Lee ${ }^{1}$, Ean-Huat Ooi ${ }^{2}$ \\ ${ }^{1}$ Sunway University, Malaysia, chiensingl@ sunway.edu.my \\ ${ }^{2}$ Universiti Tunku Abdul Rahman, Malaysia.
}

\begin{abstract}
With increasingly saturated markets and technological convergences globally, product differentiation is getting more challenging. We hypothesize that design, design-thinking, computational thinking and digital coding-storytelling aimed at encouraging reframing, and transforming would encourage analogical thinking and among the 21st century skills, ultimately, fractal thinking. Fractal thinking enables identification of patterns, which can be repeated but varied and decomposable to different levels of abstraction. In a study on expert systems analysts and programmers, curation and sharing of story-based media and analogical coding are encouraged. Next, analogical derivatives and their characteristics are mapped to PwC's worlds. These enable identification of design factors (tangible and intangible scaffolds) for the development of a code-storytelling-analogical-fractal thinking system. The significance is extension from design thinking and computational thinking to analogical and ultimately, fractal thinking; the derivation of types of analogies and their characteristics, corresponding to PwC's worlds. Future work situates learning within the Restorative Innovation-obscure-feature hypothesis framework.
\end{abstract}

Key words: Analogical Thinking, Computational-Fractal Thinking, Transformations.

\section{INTRODUCTION}

In the face of heightened competition and disruptive technologies, markets have shifted and social change has become agile, with uncertainty a constant dynamic. Industrial Revolution 4.0 to some, also poses uncertainty in terms of possible loss of certain types of jobs in the future. Ikeda and Bernstein [1] suggest crowdsourcing as one of the ways to encourage further innovations and to create new forms of human-computer interaction.

Information Systems Analysis and Design and Project Management's body of knowledge, methodologies and tools have scaffolded systemic thinking and design thinking respectively. These have partially answered the question of whether to go beyond getting people to merely contribute to contributing meaningfully and to being able to sustain such meaningful contributions/interactions. Variability in contexts also imply that there is a greater need to be not only predictive but more commonly, to be adaptive, agile and occasionally, interdisciplinary.

Carol Stubbings, Global Leader, People and Organization, PricewaterhouseCoopers (PwC) [2] in a report on PwC's analysis and prediction of the future of work in 2030, best highlights the need to reframe our minds and perspectives across disciplines. She opines that:

As individuals - actual human beings - what do we need to do to thrive and prosper in whatever the new world brings? The secret for a bright future seems to me to lie in flexibility and in the ability to reinvent yourself. If you believe that the future lies in STEM skills and that interests you, train for that. But be prepared to rethink if the world doesn't need so many programmers. If you are a great accountant who has prospered by building strong client relationships, think how you can apply that capability, without necessarily having to be an accountant. Think about yourself as a bundle of skills and capabilities, not a defined role or profession.

\subsection{Objectives}

There are popular and very successful visual coding platforms such as Scratch [3] and Alice [4] but there are also people who might like to learn coding/coding logic in a different manner due to different learning styles and different ages and the requirements of the academic course undertaken.

For instance, Gibbs' [5] website on the learning of Java expresses codes analogically. An example of a string of codes expressing panic (newer semantics) is illustrated in Fig. 1. This mode of programming however, may evidence a higher learning curve to those with lesser programming aptitude. As such, the form of the platform and scaffolding tools would need further investigation. 


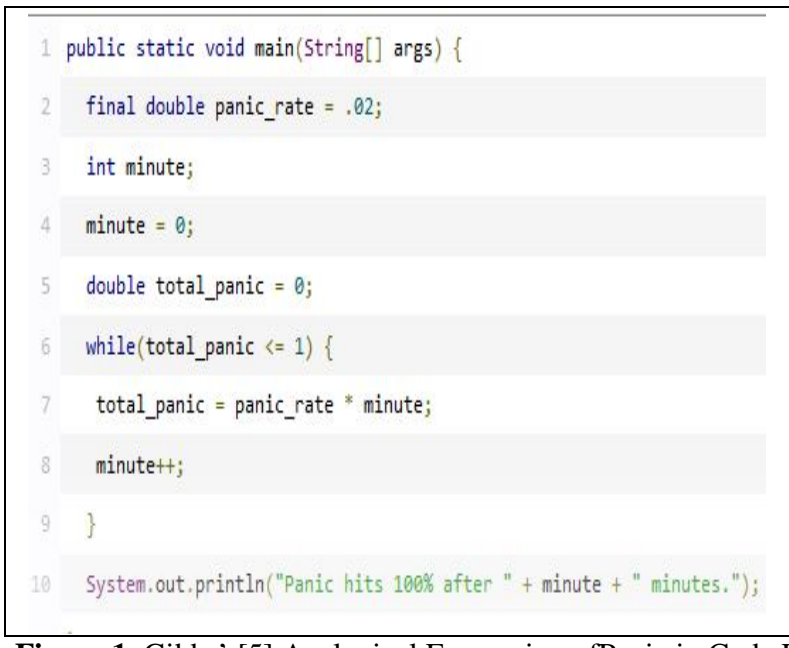

Figure 1: Gibbs' [5] Analogical Expression ofPanic in Code Form

One of Outcome-based Education's goals is transfer of learning. Prior research (Lee \& Wong, [6]), grounded in the IEEE and the Learning Sciences, summarizes 4 years of research on transfer of learning. These however, are not on coding per se.

In this study, we aim to encourage young people to think analogically and then adopt, adapt/reuse codes, i.e., recognize semantics and then fit the communication and logic with the syntax, to create their own digital stories. Hence, we hope to develop a suitable platform for developing coding and analogical thinking using Python and emulate continuous/discrete dynamical systems, such as block chain and address real-world scenarios/problems.

Our research questions are:

a) What types of analogies and design artefacts will be evidenced?

b) What are the critical success factors/barriers for analogical learning?

We are encouraged by the following:

a) Interdisciplinary reframing may encourage discovery and transfers across disciplines to create new knowledge due to a richer genetic pool;

b) The diversity of resources and the encouragement to integrate heterogeneous variety of resources in different ways is a rich area of investigation in knowledge management;

c) Affordance for different types of social engagement and affordance to encourage analogical thinking contributes towards better computer-supported-collaborative learning.

Building on prior work by the first author (Lee \& Wong, [6]), the research model for this study is illustrated in Fig. 2.

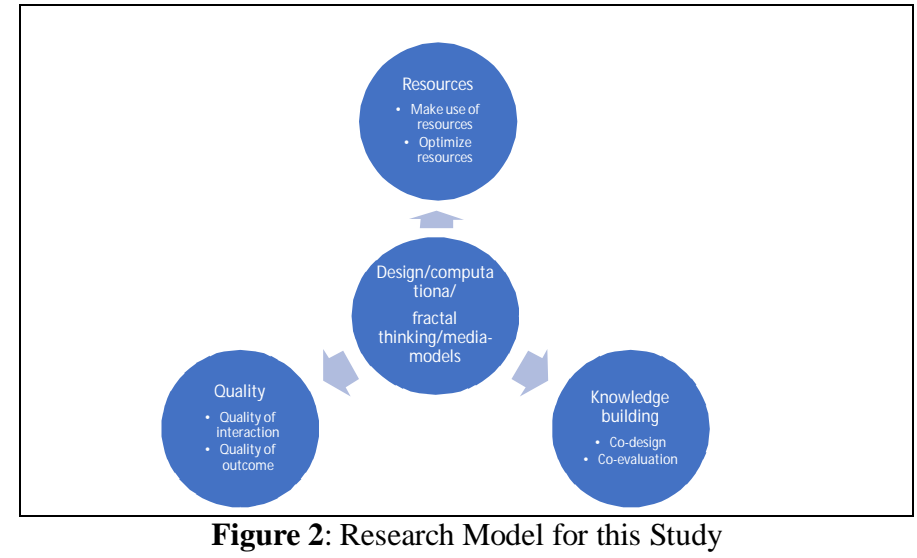

\section{RELATED WORK}

\subsection{Visual Object-Oriented Storytelling/Coding}

Scratch and Alice, two famous and popular coding initiatives, are presented in a visual contextual manner. Scratch capitalizes on decomposition and modularity of loosely coupled multimedia elements. Sprites in varied colors develop recognition of variables and values, how they can be used as computational thinking building blocks for designing, and possibilities for learning from others through sharing, modelling, reuse and transformation of sprites. Graphic editing and animation tools are included to increase fun.

Alice similarly, works with visual objects and object-oriented concepts and allows image editing. Both have evidenced huge positive success worldwide.

Ours also incorporate Art and Design into STEM learning. These serve as another possibility of stimulation and transfer. Prior work by Wong and Lee [7] and Lee and Low [8] into possible interdisciplinary transfers and application/synthesis are totally without coding. The difference between this study and Scratch and Alice lies in identifying tangible and non-tangible scaffolds, which would support analogical and/or fractal thinking.

\subsection{Computational Thinking, Analogical Thinking and Noticing as Scaffolds towards Fractal Thinking}

Wing's [9] computational thinking (CT) raises the design thinking bar higher. CT highlights: a) abstraction (multi-level, in/de/abduction, principles) and subsequently, b) decomposition of data and processes; and the importance of pattern recognition to reduce complexity amidst the traversal between abstractions and algorithm design.

Goel's [10] analogical design towards creativity involves recalling and transfer of knowledge about one design situation to another, for any level of design task in the new situation. Analogical transfer requires the use of generic abstractions, and these abstractions express the structure of relationships between generic types of objects and processes 
Fractals are usually patterns which repeat. They are often applied to obtain more effective compression in digital signal processing. An example is Tan, Chai and Poo's [11] dynamic threshold for imbalance assessment on load balancing for multicore systems. Another example is where the Sierspinki triangle (Fig. 3a) morphs into a tree.

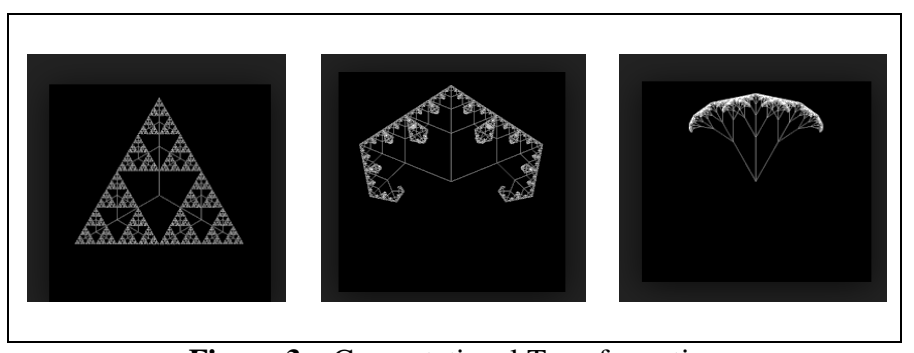

Figure 3a: Computational Transformation

Scratch has introduced fractal projects too. An example is illustrated in Fig. 3b.

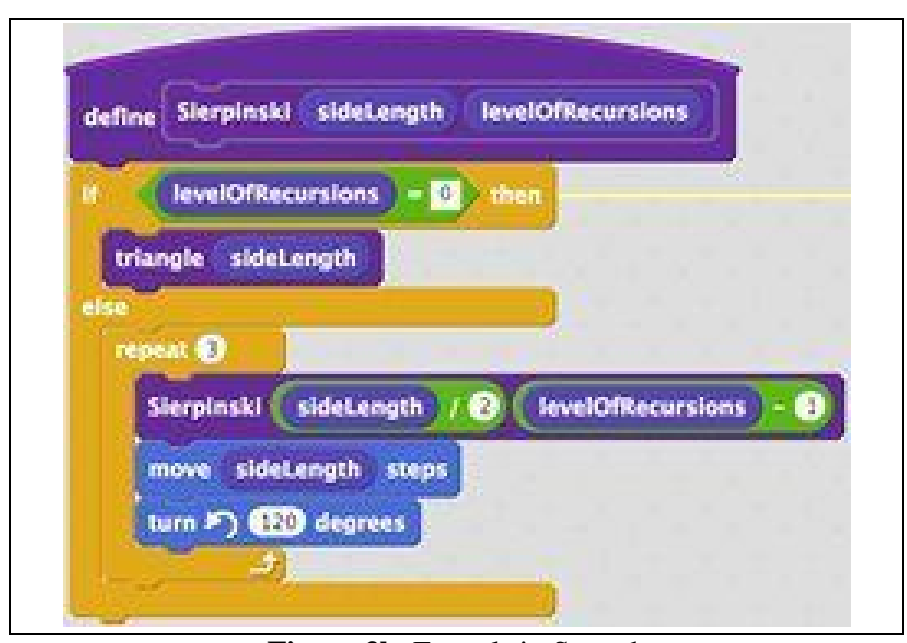

Figure 3b: Fractals in Scratch

Besides these methodologies, cognitive salience is important to help filter and reduce cognitive load. Lobato, Rhodehamel and Hohsensee's [12] socially-situated noticing framework however, investigates a broader range of phenomena, as they are interested in socially-situated explanatory accounts for transfer.

Such social situatedness considers social interactions, language, cultural artefacts, and normed practices and their contributions to the generalization of learning. They posit "noticing" as a plausible transfer process. Investigating both individual noticing and the social organization of noticing via the focusing framework, they relate the nature of students' reasoning on transfer tasks with what students notice mathematically in classrooms as varied sources of information compete for their attention. Subsequently, they account for noticing as socially situated in classroom discourse practices, features of mathematical tasks, and the nature of mathematical activity. Here, context plays a key role.

\section{METHODOLOGY}

\subsection{Sample}

Participants are computer science experts, with more than five years of working experience. Participation is voluntary. There are no financial incentives. The intention is to gather seed content and members' perceptions towards this form of learning.

\subsection{Procedure}

1. The participants are presented with a design challenge (illustrated in Fig. 4). The challenge is to post using any media to share any experiences or to share posts, which exemplify analogies. Facebook (FB) is chosen as the learning/sharing platform as it allows personal posts through an FB site as well as professional posts through a specially-created FB page.

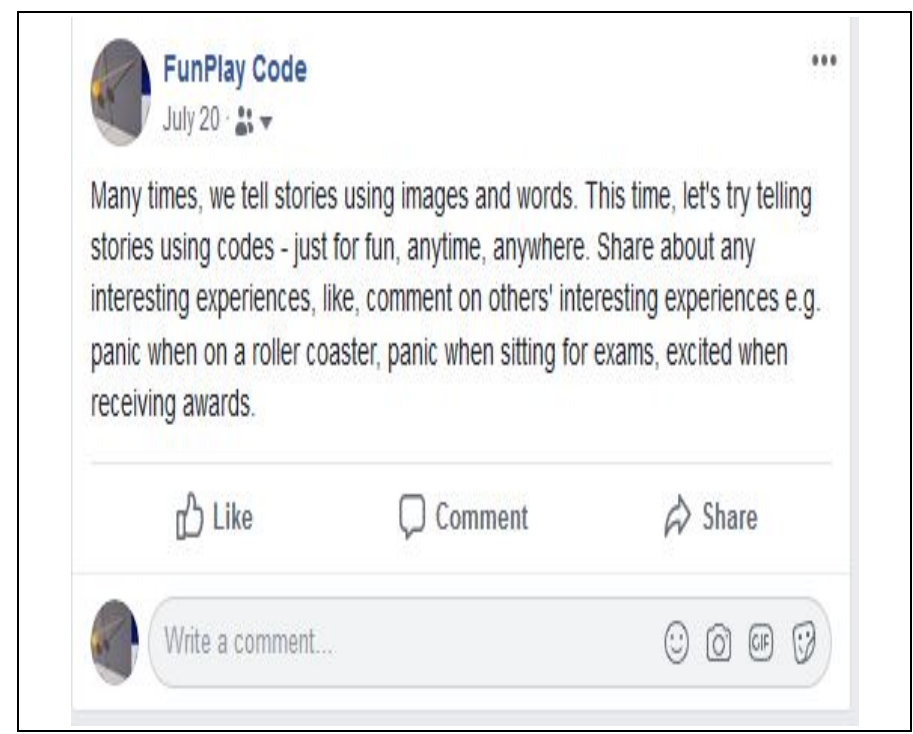

Figure 4: Design Challenge

2. Participants are requested to participate as how they would have others participate. They can post any media in any way they wish, share, comment and like.

3. The categorization of analogical contributions is based on PwC's [2] worlds, first introduced in [6], but with an additional world, i.e., the yellow world (humans first). Subsequent categorization is based on thematic analysis. 


\section{SAMPLE ANALOGICAL CONTRIBUTIONS}

\subsection{Analogical Posts (Yellow world: Humans first)}

Two members posted on what they perceived as fun. One member's posts revolve around his and his daughter's adventures in HK Disneyland, and various parts of the world. His posts add a real human face to user experience in terms of fun and happiness. Another member's post revolves around international collaboration and fun times with colleagues. These posts reflect on the yellow world: humans come first.

\subsection{Analogical Music Video (Green World: Companies Care)}

Another member posted an analogical video, i.e., Mukaiya's [13] video on 200 distinct chimes. He uniquely crafted unique chimes for over 110 stations in Japan (Fig. 5). The artefacts capture the essence of reframing, stories, design thinking, computational thinking, form and function.

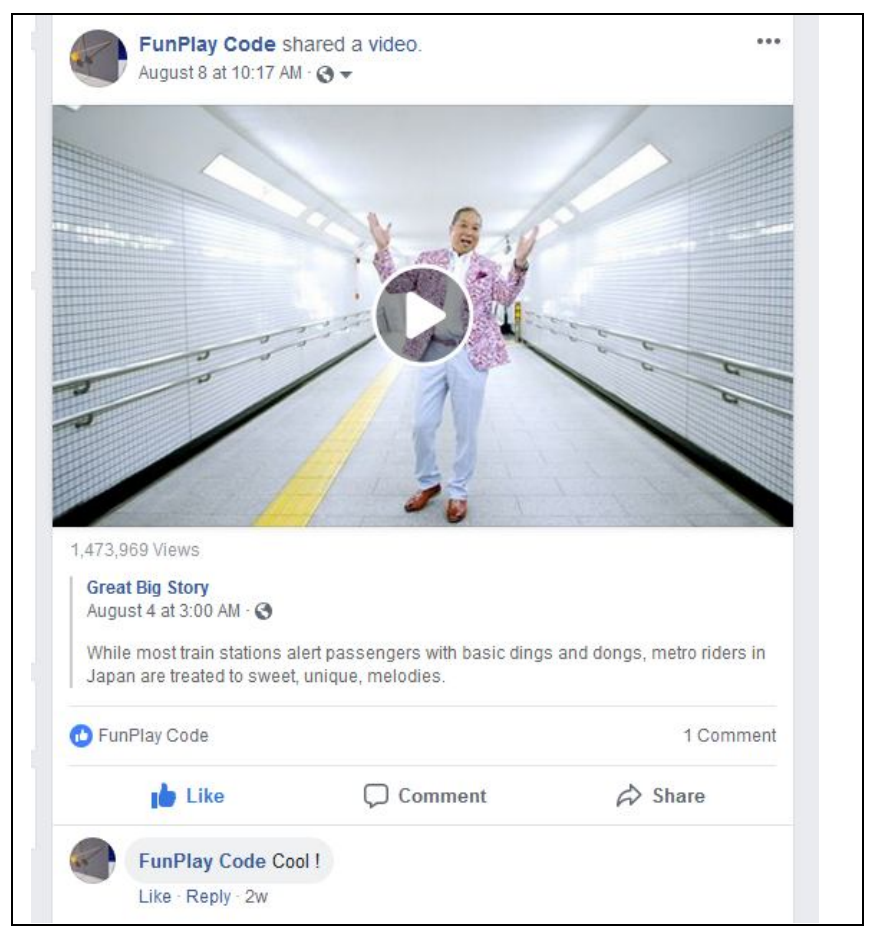

Figure 5: Mukaiya's Music as Parts of a Great Big Story [13]

\subsection{Analogical Art/Patterns/Doodles (Red World: Agility And Speed)}

An example of the use of analogical patterns is illustrated in Fig. 6a (communicative connectivity). The Malaysian doodles group adds another dimension. An example by Mr. Weng-Soon Chong (with permission) is illustrated in Fig. 6b.

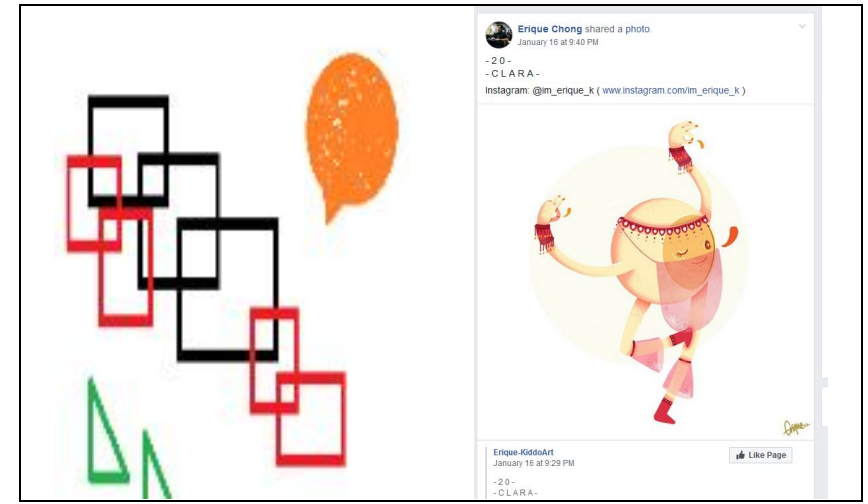

Figure 6a, b: Analogical Minimalism

\subsection{Analogical code (Red world: Agility and speed)}

A user can create one or more stories. Each story may contain posts by the creator of the story and any other users. Similar to Gibb [5], each story is represented as a class and each post can be represented as a method within the class. A general template of the class file is shown below, followed by a sample code which is executable.

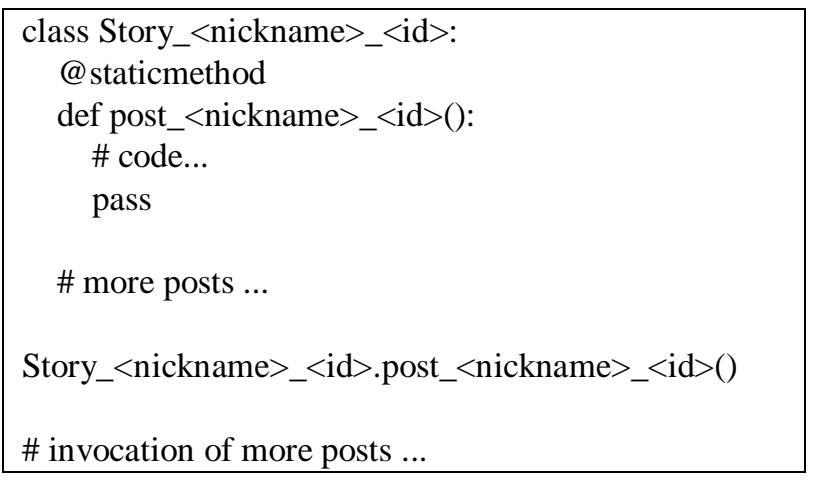

A member of the group suggested creating a story for the challenge: What can we do with the block poweroftwo?

Two members participated and communicated similar to coding-testing pairs. In Iteration 1,a member combined two posts, debugged and converted them into methods. In iteration 2 , hashtags are used for user identity.

In iteration 3, another member suggested roles to be used since it is a small group. Although a computing storytelling initiative, identity stands out not only due to concerns with credit assignment, but also with the relation between identity and roles. This highlights the importance of the communicative aspects in designing computing contexts, platforms and tasks as well as the roles of each team member, similar to agile methodology.

The codes for iteration 4 are presented in Fig. 7 below. 


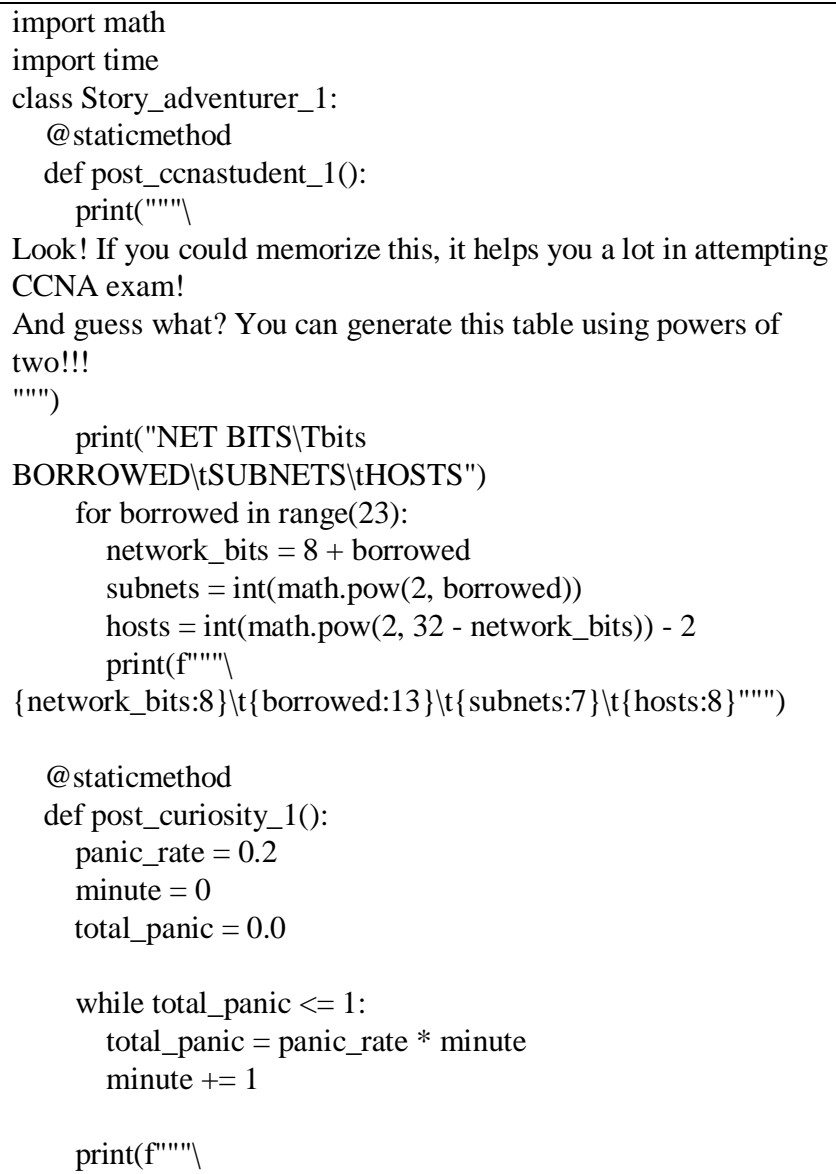

Panic hits $100 \%$ after \{minute \} minutes trying to memorize valid values of IPv4 subnet mask for CCNA exam!

"'"')

@ staticmethod

def post_poweroftwo_1(): print("'"')

We can play a game based on the powers of 2 to understand how the figures in the subnet mask are derived.

So we will be looping but in each loop, the challenge will be different. Are you ready?

"'"')

for $\mathrm{i}$ in range $(10,-1,-1)$ :

print(i)

time.sleep(1)

@ staticmethod

def post_poweroftwo_2():

print("This is a series of the powers of 2")

for $\mathrm{i}$ in range(11):

power_of_two $=\operatorname{int}($ math.pow $(2, i))$

$\operatorname{print}\left(\mathrm{f}^{\prime} 2^{\wedge}\{\mathrm{i}: 2\}=\{\right.$ power_of_two:3 $\left.\} "\right)$

@ staticmethod

def post_poweroftwo_3():

print("These are valid values of IPv4 subnet mask octets")

for $i$ in range $(9)$ :

power_of_two $=\operatorname{int}(\operatorname{math} . p o w(2, i))$

mask_value $=256$ - power_of_two

print(mask_value)
Story_adventurer_1.post_poweroftwo_1()

Story_adventurer_1.post_poweroftwo_2()

Story_adventurer_1.post_poweroftwo_3()

Story_adventurer_1.post_curiosity_1()

Story_adventurer_1.post_ccnastudent_1()

Figure 7: Sample Codes

\section{DISCUSSION}

The research questions are:

Research question 1: What types of analogies and design artefacts will be evidenced?

From the examples in Section 4, we derived types of analogies corresponding to PwC's worlds and their respective characteristics. These intangible scaffolds are presented in Table 1. It is interesting to note how experts focus on representativeness in form and function. This finding also reflects what Scratch is trying to teach young scientists and programmers. We also note how introspective factors are reflected in external forms.

Table 1: Analogical Characteristics Derived

\begin{tabular}{|c|c|c|}
\hline World & Introspective & Extrospective \\
\hline Yellow & $\begin{array}{c}\text { Family fun in } \\
\text { diverse contexts }\end{array}$ & $\begin{array}{l}\text { Career achievements } \\
\text { in diverse contexts }\end{array}$ \\
\hline Green & $\begin{array}{c}\text { Reframing } \\
\text { (memory/episodic } \\
\text { differentiation) }\end{array}$ & $\begin{array}{l}\text { User experience based on } \\
\text { computational thinking } \\
\text { (form and function) }\end{array}$ \\
\hline Red & $\begin{array}{c}\text { Minimalist/ } \\
\text { representative }\end{array}$ & Agility/representative \\
\hline
\end{tabular}

In another study by Lee and Jiang [14], preliminary findings on Scratch fractal projects highlighted that computational thinking is best evidenced when the student communicates in diverse forms for different functions. This finding confirms the extrospective aspects in Table 1 and bridges the design of human-computer interaction with the design of learning environments for computational-fractal thinking.

Research question 2: What are the critical success factors/barriers?

Two key socio-technological factors in Ventakesh and Davis' [15] Technology Acceptance Model are usefulness and ease of use. Our findings support these factors, especially with regards to usefulness.

Furthermore, Resnick's [16] guidelines e.g. expressivity, scalability and adaptability for the development of creativity tools are reconfirmed. These critical success factors form the tangible scaffolds in our to-be-developed tool. 


\section{FUTURE WORK WITHIN A RESTORATIVE INNOVATION FRAMEWORK}

To be sustainable, we need a bigger picture than pure research. To us in the emerging economies, we would like to apply Cha's [17] Restorative Innovation framework (Fig. 8). In this economically-grounded framework, innovations contribute back to health, the community and the environment, with equal emphases on design thinking, social innovation and quality principles. These will form the topics for discussion.

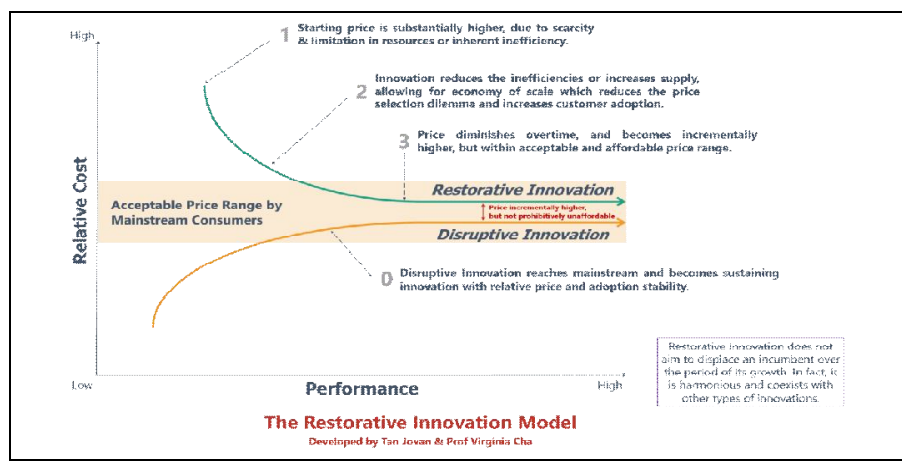

Figure 8 : [17]'sRestorative Innovation Framework

As granularity and modularity are natural in crowd-sourced content generation, open to any subject, one initial version will be on storytelling and another, on IPv4 or IPv6. To trigger more thought, McCaffrey and Spector's [18] obscure feature hypothesis and gamification approaches such as by $[19,20]$ would likely come into the picture too.

\section{SIGNIFICANCE}

The significance of this humble initiative in a developing country lies in:

a) extending from design thinking and computational thinking to analogical-fractal thinking;

b) identification of critical success factors for the design of the platform: need for agent-based feedback, links to open context-sensitive educational resources (rich yet granular, modular multimedia), syncing with personal beliefs;

c) given the granular and modular nature of blocks of codes, possible emulation of block-chain;

d) with the richness of the local culture, identity and talents and with the support and help from the more developed countries, possible emergent useful creative outcomes;

e) with the development of a compiler to help debug the codes, to venture into different mixed reality and ambient environments;

f) this study may also link with other initiatives on intelligent social media recommendation such as by Wong and Lee [21] and Lau and Lee [22] and Biswas [23].

\section{CONCLUSION}

Learning and transfer of learning are key concerns of Outcome-based Education (OBE). We have investigated affordances for different types of social engagement for collaborative/competitive learning/ human-computer interaction. Through this preliminary initiative, we have identified intangible and tangible scaffolds to encourage analogical thinking, to reduce the gap between reality (the context), and the learning task. Furthermore, the diversity of resources in the European, UK and US Open Educational Resources and Open Data initiatives provide rich sources for analogical thinking. We also acknowledge that there is much room for improvement such as interlinking with libraries in Github and Stackoverflow and embedded compilers and towards this end, we will be developing a more user-friendly, attractive gamified tool.

\section{ACKNOWLEDGEMENT}

This project was inspired by an analogical post posted by $3 \mathrm{G}$ InfoCom Pte Ltd., Malaysia, on its FB site in 2012-2013. Initially mooted during a brainstorming session organized by the Malaysian Invention and Design Society, FunPlayCode was mooted as one of the projects under STEM Asia with Dr. Vui-Kien Liau, PSB Academy, Singapore. He vetted through the initial paper. The first author thanks Prof. Adrian David Cheok; Dr. Daniel Loy (PetroSains) and Dr. Ian Chai (Multimedia University, Malaysia), Ms. Mindy Yin-Li Wong. Thanks also to Prof. Ashok K. Goel for featuring computational art at the 2011 Creativity and Cognition conference, MIT for inspiration on granular computing, Dr. K. Daniel Wong for prior collaboration on design-computational thinking in Universiti Tunku Abdul Rahman and Sunway University, which led to this paper and Prof. Bo Jiang for his support towards this study and fractal thinking.

\section{REFERENCES}

1. Ikeda, K., \& Bernstein, M. S. 2016. Pay It Backward: Per- Task Payments on Crowdsourcing Platforms Reduce Productivity. CHI'16, May 07-12, 2016, San Jose, CA, USA. https://doi.org/10.1145/2858036.2858327

2. Stubbings, C. 2018. Workforce of the future: The competing forces shaping 2030. Price Waterhouse Coopers (PwC).

3. Scratch https://scratch.mit.edu/

4. Alice https://www.alice.org/

5. Gibbs, M. 2018. https://study.com/academy/lesson/while-loops-in-java-e xample-syntax.html, last accessed 2018/07/29

6. Lee, C. S., \& Wong, K. D. 2018a. Design - computational thinking, transfer and flavors of reuse: Scaffolds to Information and Data Science for sustainable systems in Smart Cities. International IEEE International Conference on Information Reuse and Integration, IEEE 
Computer Society, Salt Lake City, Utah, July 7-9, 2018, 225-228.

7. Wong, C. K., \& C. S. Lee. 2016. A better understanding of gamification to improve digital lifestyles. IEEE International Conference on Virtual Systems and Multimedia, Kuala Lumpur, Malaysia, 1-8. https://doi.org/10.1109/VSMM.2016.7863214

8. Lee, C. S., \& Low, S. H. S. 2017. Developing interest to share and craft based on the Technology Acceptance Model. International Conference on Computational Thinking, July 13-15, 2017, Hong Kong.

9. Wing, J. M. 2006. Computational Thinking. Communications of the ACM, 49(3), 33-35. https://doi.org/10.1145/1118178.1118215

10. Goel, A. K. 1997. Design, Analogy, and Creativity. IEEE Expert, 62-70. https://doi.org/10.1109/64.590078

11. Tan, I. K. T., Chai, I., \& Poo, K. H. 2013. Dynamic threshold for imbalance assessment on load balancing for multicore systems. Computers and Electrical Engineering Journal, 39 (2), 338-348.

12. Lobato, J., Rhodehamel, B., \& Hohensee, C. 2012. "Noticing" as an alternative transfer of learning process, Journal of the Learning Sciences, 21 (3), 433-482.

13. Mukaiya, M. 2018. In Tokyo, These Trains Jingle All the Way. Great Big Story. https://www.youtube.com/watch?v=nSG5IkRA9BE Last accessed. Aug 3, 2018

14. Lee, C. S. \& Jiang, B. 2019. Assessment of Computational Thinking (CT) in Scratch fractal projects: Towards CT-HCI scaffolds for analogical-fractal thinking," International Conference on Computer-Supported Education, Crete, Greece May 2-4, 2019.

15. Venkatesh, V., Davis, F. D. 2000. A theoretical extension of the technology acceptance model: Four longitudinal field studies. Management Science, 46(2), 186-204. https://doi.org/10.1287/mnsc.46.2.186.11926

16. Resnick, M. 2005. Designing for Wide Walls. https://design.blog/2016/08/25/mitchel-resnick-designin g-for-wide-walls/

17. Cha, V. 2018. Restorative innovation framework. Online: https://www.restorativeinnovation.com/

18. McCaffrey, T., Spector, L. 2012. Behind every innovative solution lies an obscure feature. Knowledge Management \& E-Learning, 4 (2).

19. Wu, Q, Zhu, Y., \& Luo, Z. 2015. Gamification approach to getting students engaged in academic study. Bulletin of the IEEE Technical Committee on Learning Technology, 17 (4), 26- 29.

20. Lee, C. S., \& Wong, K. D. 2018b. Deriving a gamified learning-design framework towards sustainable community engagement and mashable innovations in Smart Cities: Preliminary findings. International Journal of Knowledge and Systems Science (IJKSS), 9(1), 1-22. https://doi.org/10.4018/IJKSS.2018010101

21. Wong, Y. L., \& Lee, C. S. 2011. Creative storytelling enhanced through social media and intelligent recommendation. Creativity \& Cognition, 399-400.

https://doi.org/10.1145/2069618.2069715
22. Lau, S. B. Y., \& Lee, C. S. 2012. Enhancing Collaborative Filtering of Learning Resources with Semantically-Enhanced Social Tags. International Conference on Advanced Learning Technology, 281-285. https://doi.org/10.1109/ICALT.2012.102

23. R. Biswas, S. Roy. Content Based CT Image Sign Retrieval using Fast Discrete Curvelet Transform and Deep Learning. International Journal of Advanced Trends in Computer Science and Engineering. Volume 8, No.3, May - June 2019 https://doi.org/10.30534/ijatcse/2019/80832019 